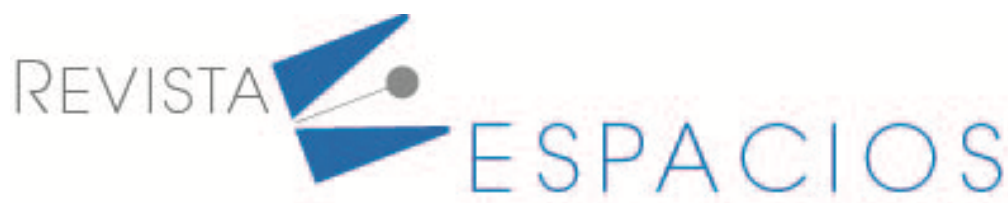

\title{
Revistas académicas ¿resiliencia o los estertores de la investigación en Venezuela?
}

\section{Academic journals. Resilience or death agony of Research in Venezuela?}

\author{
MERCADO, Alexis ${ }^{1}$ \\ SÁNCHEZ-ROSE, Isabelle ${ }^{2}$ \\ VESSURI, $\mathrm{Hebe}^{3}$
}

\begin{abstract}
Resumen
Venezuela experimenta un desmantelamiento de la investigación y desarrollo tecnológico. Los indicadores muestran daños casi irreversibles en las capacidades de producción, difusión y uso del conocimiento, comprometiendo severamente las posibilidades de acompañar las profundas transformaciones sociotécnicas globales y garantizar el bienestar. Las publicaciones académicas sufren una merma de contribuciones de autores nacionales, además de severas limitaciones presupuestarias. Aun así, muchas mantienen continuidad debido a esfuerzos de los editores y la conformación de redes colaborativas ¿Evidencia esto resiliencia, o son los estertores de la investigación?

Palabras clave: publicaciones académicas, investigación, resiliencia
\end{abstract}

\begin{abstract}
Venezuela affronts a dismantlement of its research and technological development capacities, affecting the production, diffusion, and use of knowledge. This affects the possibilities of accompanying the global sociotechnical transformations and guaranteeing the well-being. Academic publications suffer a severe decrease in contributions from national authors and budget restrictions. Even so, many of them remain active thanks to the efforts of the editors and the conformations of collaborative networks. Does this evidence resilience, or is it the death rattle of research?
\end{abstract}

Key words: academic publications, research, resilience

\section{Introducción}

Las publicaciones científicas, como instrumentos fundamentales de difusión e intercambio del conocimiento, pueden ofrecer un panorama razonable de la situación del ecosistema de investigación e innovación de un país, una región e, incluso, de una institución. En las últimas tres décadas, han experimentado cambios sin precedentes, provocados por el extraordinario crecimiento del mundo digital, que ha afianzado el formato electrónico como medio principal de divulgación; ha posibilitado el surgimiento de nuevas revistas debido a las

\footnotetext{
${ }^{1}$ Profesor Emérito. Centro de Estudios del Desarrollo. Universidad Central de Venezuela. Venezuela. alexisms60@gmail.com

2 Profesora Asociada. Centro de Estudios del Desarrollo. Universidad Central de Venezuela. Venezuela.abulafia2@gmail.com

${ }^{3}$ Investigadora Emérita. Centro de Estudio de la Ciencia. Instituto Venezolano de Investigaciones Científicas. Venezuela. hvessuri@gmail,com
} 
economías que ofrece en cuanto a edición, y ha potenciado movimientos que procuran una mayor difusión del conocimiento como el Open Access, que buscó disputar a las revistas electrónicas basadas en suscripción, el predominio de las publicaciones académicas, si bien el panorama se ha complicado en los últimos años con la multiplicación de formatos híbridos (Yokoi, 2013; Packer, 2019; Mirowski, 2018; Knöchelmann, 2020). En todo caso, no ha habido una reducción de las asimetrías del acceso al conocimiento debido, en gran medida, a las limitaciones de acceso a las tecnologías digitales. La pandemia del COVID-19 aceleró la irreversibilidad de los cambios, mas agudizó, también, los problemas.

En Venezuela, acompañando la implantación y el desarrollo de la investigación, hubo un interesante proceso de creación de publicaciones académicas, que experimentó gran impulso en la década de los noventa y la primera de este siglo gracias a políticas institucionales explícitas de las universidades nacionales, la implementación del programa de apoyo a las publicaciones científicas del Consejo Nacional de Investigaciones Científicas y Tecnológicas (CONICIT) en 1996 y de programas de estímulo para preservar capacidades de investigación e impulsar la publicación académica local, destacando, desde el Estado, el Programa de Promoción de la Investigación (PPI), con criterios de evaluación que estimulaban la productividad científica.

En este siglo, las publicaciones venezolanas acompañan estas transformaciones, migrando hacia los formatos electrónicos y el acceso abierto, lo que contribuiría a su continuidad y vigencia. Sin embargo, cambios en la política a partir de 2009, en los que privó el sectarismo, eliminó el programa de apoyo del Estado, y pretendió crear normativas adecuadas al proyecto político. Se elimina cualquier apoyo a las revistas "autónomas" precarizándolas. La agudización de la crisis a partir de 2017, agravó la situación al desaparecer cualquier financiamiento desde las propias universidades, experimentándose un retroceso importante de la visibilidad e impacto. A pesar de ello, el número de revistas que continúan activas muestra niveles importantes de sobrevivencia, lo que llevó a analizar las causas, evidenciándose el importante papel que desempañan los editores, y la conformación de redes colaborativas, que asumen desinteresadamente todas las actividades inherentes a la publicación.

Se analiza en primer lugar la creación de las publicaciones de las tres universidades autónomas que poseen el mayor número de revistas científicas, a saber: la Universidad Central de Venezuela (UCV), la Universidad del Zulia (LUZ) y la Universidad de Los Andes (ULA) a objeto de observar su evolución, considerándolas como mecanismos de difusión y legitimación de la investigación, procurando identificar factores institucionales que puedan haber estimulado su aparición y trayectoria. Seguidamente, se hace una revisión de la continuidad de las publicaciones y del impacto considerando su inclusión en repositorios académicos internacionales. Finalmente, a través de entrevistas con un grupo de editores, académicos de alto nivel, se analizan los esfuerzos que explican la sobrevivencia de la publicación académica en el país.

Para los fines del estudio se elaboró una base de datos con la información recopilada de los repositorios de estas universidades, como fuente inicial, complementada con la obtenida del Registro de Revistas Venezolanas de Ciencia y Tecnología (REVENCYT), REDALYC, Open Journal Report, Scopus y Latindex. Como resultado se cuenta con información de las revistas académicas de estas universidades desde 1936 hasta diciembre de 2021.

\section{Auge y caída de la investigación}

La implantación de las disciplinas científicas modernas en Venezuela tiene antecedentes con la creación de algunas cátedras e institutos de investigación en especialidades médicas, agricultura y zootecnia, ciencias naturales, ciencias sociales (antropología y psicología) y filosofía en la Universidad Central de Venezuela (UCV) entre las décadas del treinta y cincuenta del siglo pasado. Tres hitos: la creación del Consejo de Desarrollo Científico y Humanístico y la Facultad de Ciencias en la UCV 1958, y del Instituto Venezolano de Investigaciones 
Científicas en 1959 le darán un impulso significativo (Díaz, Texera y Vessuri, 1983), constituyéndose en los modelos de apoyo y práctica, entiéndase una investigación realizada en universidades y centros de investigación públicos, promovidos con financiamiento público desde organismos de promoción con autonomía, registrándose un rápido crecimiento en los siguientes veinte años. La creación del CONICIT en 1967, de la mano de varios de los responsables de los hitos anteriores, estableció el espacio institucional de negociación con el Estado, consolidando una pequeñita república local de la ciencia (cf. Polanyi, 2014). A partir de 1969 se irá incrementando el otorgamiento de recursos directos por parte del Estado, hasta 1979 (gráfico 1).

Esto no significa que haya sido un proceso del todo virtuoso. La ciencia pudo haber procurado aproximarse más a la sociedad y contar con mayor apoyo del Estado. Sin embargo, el compromiso de éste no estuvo ligado a prioridades estratégicas más allá de garantizar un cierto nivel de funcionamiento de la actividad científica. Por su parte, los científicos con influencia, fueron esenciales en la toma de decisiones de las agencias de promoción impulsados, en el mejor de los casos, por los criterios de la relevancia interna de las disciplinas científicas, cuando no por motivaciones personales (Vessuri, 2005). Así, una consecuencia importante fue la débil creación de capacidades de producción de conocimiento aplicado y de desarrollo tecnológico, debido a la implantación de políticas ofertistas limitadas a promover la investigación (Mercado, Testa, Rengifo, Goméz y Patruyo, 1999).

La crisis de los ochenta, afectó la capacidad científica en construcción. La caída del salario real, y la disminución del financiamiento de la investigación, muy marcada en el segundo lustro (gráfico 1), frenaron su crecimiento, coincidiendo esto con la culminación de la carrera profesional de las primeras generaciones de investigadores, que empezaron a jubilarse. Comienzan a observarse problemas en el funcionamiento por la disminución de la dotación de equipos e insumos, y a comprometerse la conformación de las generaciones de relevo.

Gráfico 1

Presupuesto del CONICIT (1970-2001)

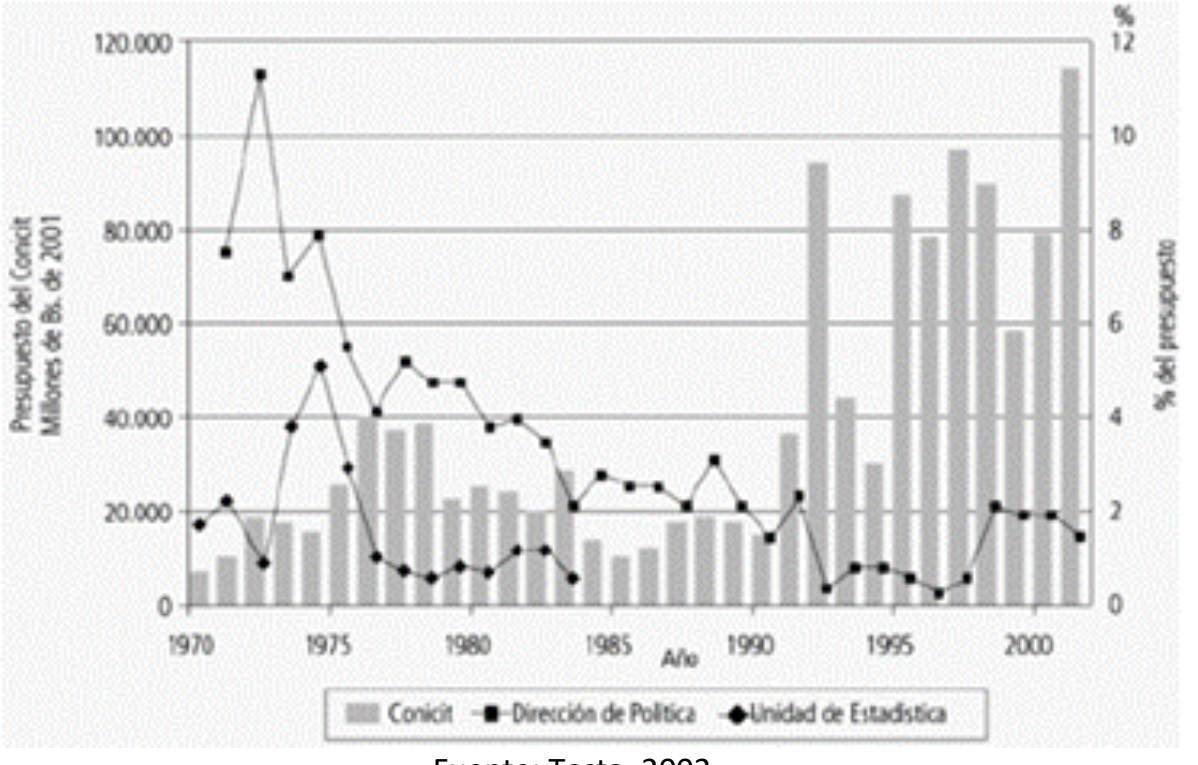

Fuente: Testa, 2002

En los noventa, en medio de una gran inestabilidad sociopolítica, y con la noción de Sistema Nacional de Innovación dominando la política científica y tecnológica, se pretende un cambio en el estímulo a la actividad procurando mayor pertinencia económica, contando con la orientación y respaldo de organismos multilaterales. Particularmente importantes fueron los programas BID I y BID II, que consideraron préstamos para renovar infraestructura y equipos, e implementar programas que aproximaran la investigación a la industria. Estos contribuyeron a la recuperación y crecimiento del financiamiento (gráfico 1). Sin embargo, dichos programas 
tuvieron un alcance limitado; prácticamente no hubo transferencia de conocimientos a la industria, porque no consideraban adecuadamente las capacidades y necesidades de ambos sectores.

Paralelamente, se implementaron programas de estímulo para preservar capacidades de investigación e impulsar la publicación académica local. Desde el Estado destacó el Programa de Promoción de la Investigación (PPI), con criterios clásicos de evaluación, en especial la productividad científica, que contribuyeron a mantener su funcionamiento, promoviendo la cultura de la publicación. Así, la poca efectividad de los programas que procuraban más pertinencia económica combinados con estímulos usuales de la investigación, resultó en cambios cuantitativos más no de orientación en el comportamiento de la república de la ciencia (comunidad de investigadores).

Debido a la crisis, en especial la inestabilidad sociopolítica, comienza a notarse el fenómeno de la emigración que hasta entonces había sido muy baja, concentrada especialmente en los pocos investigadores que se exiliaron durante la Dictadura de Pérez Jiménez. Diez, Freites, García-Pérez, Ordóñez, Pineda, Requena \& Romero (2020) en estudio sobre investigadores venezolanos con publicaciones (período 1960 - 2018), con base a información de la base de datos BIBLIOS, señalan que, a partir de 1994, ésta crece progresivamente hasta finales de siglo XX.

A inicios del nuevo siglo se pretende dar un impulso a la ciencia y la tecnología, otorgándoles rango constitucional; se procura consolidar una nueva institucionalidad, creándose el Ministerio de Ciencia y Tecnología, se promulga la Ley Orgánica de Ciencia, Tecnología e Innovación, se diseñan programas de divulgación e inclusión, y se crean instituciones para el desarrollo tecnológico. En contraposición, comienza un distanciamiento con las universidades autónomas, productoras del grueso de la investigación del país, que se mostraban críticas frente a algunas acciones del Gobierno. El apoyo a la investigación y desarrollo tecnológico (I+DT) se centra en los institutos adscritos al Ministerio, las universidades experimentales y las nuevas universidades bolivarianas (Mercado, Ávalos, Sánchez-Rose, Cervilla, López \& Vessuri, 2020).

A finales de esa década ocurre un quiebre institucional. Se procuró alinear la política científica y tecnológica al proyecto político del chavismo, tornándose marcadamente sectaria. Así, a pesar de la bonanza económica producto del boom petrolero, las universidades públicas autónomas ven mermar progresivamente sus presupuestos, comenzando a experimentar un sostenido deterioro que se agudiza a partir de 2013 debido a la caída del ingreso petrolero y el derrumbe de la economía. Desde entonces, se acelera el deterioro institucional, decayendo ostensiblemente la estructura técnica del Estado en CyT, desmejorando notablemente la gestión (Ibídem). En cuanto a la migración de investigadores, ésta se dispara a partir de 2002. De los 2.235 investigadores identificados en el estudio citado, 2084, un 85\%, lo hicieron a partir del año 2000 (Diez, Freites, García-Pérez, Ordóñez, Pineda, Requena \& Romero, 2020), generando fracturas importantes en, prácticamente, todas las áreas de conocimiento.

La situación se agravó notablemente en los últimos años. Los severos recortes financieros del estado a las universidades autónomas, sobre todo desde 2015 cuando los déficits se ubicaban en torno al 67\%. Empeoraron en 2019-2020, llegándose a una asfixia presupuestaria que alcanza una media del 95\% (Cuadro 1) condenándolas literalmente a su paralización (Aula Abierta, 2021). Esto, aparte de la disminución del personal, ha generado el cierre de postgrados y el deterioro y obsolescencia de instalaciones, factores que, al final, se traducen en una pérdida importante de capacidades de investigación y de la posibilidad de ofrecer formación académica de calidad.

La pandemia del COVID 19, literalmente dejó desiertas a las universidades, aunque hay que reconocer que, evidenciando resiliencia, hubo respuestas mediante medios virtuales que preservaron e, incluso, promovieron nuevas experiencias fundamentalmente de formación. 
Cuadro 1

Déficits presupuestarios de algunas

universidades nacionales autónomas

\begin{tabular}{|l|c|c|c|c|c|c|}
\hline \multirow{2}{*}{\multicolumn{1}{c|}{ Institución }} & \multicolumn{7}{c|}{ Año } \\
\cline { 2 - 7 } & 2015 & 2016 & 2017 & 2018 & 2019 & 2020 \\
\hline Universidad de Los Andes & $62,2 \%$ & $70,4 \%$ & $46,0 \%$ & $75,0 \%$ & $80,0 \%$ & $97,8 \%$ \\
\hline Central de Venezuela & $67,3 \%$ & $68,0 \%$ & $70,0 \%$ & $80,0 \%$ & $68,1 \%$ & $90,2 \%$ \\
\hline Universidad del Zulia & $67,8 \%$ & -- & $58,0 \%$ & $70,0 \%$ & $99,8 \%$ & $97,8 \%$ \\
\hline Universidad de Oriente & $72,0 \%$ & $71,1 \%$ & $70,0 \%$ & $89,2 \%$ & $89,2 \%$ & -- \\
\hline
\end{tabular}

Fuente: Aula Abierta (2021)

El desplome de la economía - hay que recordar que entre 2013 y 2020 el país perdió más del 75\% de su PIBhizo que la crisis alcanzara a todo el ecosistema de investigación e innovación. En 2016, se paralizó el Programa de Estímulo a la Innovación y la Investigación (PEII), que en 2011 sustituyó al PPI. Indicadores oficiales evidencian que las actividades asociadas a este programa habían mermado significativamente para ese último año. Entre 2013, año en que se reportan cifras topes de los proyectos y 2016, hubo una caída de $80 \%$, siendo las áreas más afectadas Medicina y Salud, Ciencias Naturales y Exactas y Humanidades (cuadro 2).

\section{Cuadro 2}

Proyectos de investigación por área de conocimiento acreditados al PEII

\begin{tabular}{|l|c|c|c|}
\hline \multirow{2}{*}{\multicolumn{1}{c|}{ Área de conocimiento }} & \multicolumn{2}{c|}{ años } & Variación \\
\cline { 2 - 3 } & 2013 & 2016 & $2013 / 2016$ \\
\hline Ciencias naturales y exactas & 1711 & 218 & $-87 \%$ \\
\hline Ciencias agrícolas & 1103 & 279 & $-75 \%$ \\
\hline Ciencias sociales & 1260 & 516 & $-59 \%$ \\
\hline Humanidades & 883 & 81 & $-91 \%$ \\
\hline Ingeniería & 1102 & 223 & $-80 \%$ \\
\hline Medicina y salud & 749 & 51 & $-93 \%$ \\
\hline Total & 6808 & 1368 & $-80 \%$ \\
\hline
\end{tabular}

Fuente: ONCTI, 2017

Sin hacer valoración sobre los proyectos, debido a que los criterios establecidos en el programa eran muy amplios y laxos, los datos evidencian la importante caída de la actividad para ese momento, con el agravante que esto se agudizó en los últimos cinco años. Puede aseverarse que las actividades de I+DT en Venezuela se encuentran hoy severamente comprometidas, y no sería exagerado decir que en extinción. ¿Cómo ha afectado esto la actividad de las publicaciones científicas?

\section{Las publicaciones científicas en Venezuela}

Debe observarse que las revistas científicas en América Latina han sido producidas casi en su totalidad por las universidades públicas. Venezuela no es ajena a esta tradición. Para los fines del estudio, se toman como elemento de análisis los repositorios institucionales de publicaciones de las tres universidades autónomas que poseen el mayor número de revistas científicas del país. A saber: la Universidad Central de Venezuela (UCV), la Universidad del Zulia (LUZ) y la Universidad de Los Andes (ULA). Su análisis permite tener un panorama bastante aproximado de la situación general de las publicaciones académicas. A los fines de la organización de la información, se emplea la clasificación de áreas disciplinarias de la UNESCO. 


\subsection{Creación y evolución de las publicaciones científicas}

Se hace, en primer lugar, un análisis histórico de la creación de las revistas, a objeto de observar las dinámicas en la evolución de las disciplinas, su creación como mecanismos de difusión de la actividad y legitimación, procurando, para ello, identificar hitos y factores institucionales que puedan haber estimulado su surgimiento y trayectoria.

Hasta 1959, momento en que comienzan a consolidarse las disciplinas científicas modernas en Venezuela, aparte de Acta Científica Venezolana, creada como mecanismo de divulgación de la Asociación Venezolana para el Avance de la Ciencia (ASOVAC) en el mismo año de su fundación (1950), en las tres universidades analizadas existían once revistas, diez de ellas en la UCV, en las áreas de agricultura (2), ciencias naturales ${ }^{4}$ y matemáticas (3), salud (3), ciencias sociales (1) (ciencias jurídicas) y una en humanidades (filosofía). Una Revista de LUZ, aún vigente, que es multidisciplinaria (cuadro 3). En su mayoría, constituían los medios de divulgación de las cátedras e institutos de creación reciente citadas arriba.

Durante el período de consolidación e institucionalización de la investigación (1960-1980) surgieron en estas instituciones diecisiete revistas, nueve en la UCV, cinco en la ULA y tres en LUZ, destacando en número Salud y Servicios Sociales (4), Ciencias Naturales y Matemáticas (3) y Ciencias Sociales (3). Desde finales de los sesenta, en las facultades y escuelas de ciencias, comienza a prestarse importancia a la publicación en revistas internacionales, lo que quizás haya limitado el interés en crear publicaciones nacionales. Destaca el surgimiento de las publicaciones en el interior del país, la aparición de las primeras revistas en ingeniería industria y construcción (cuadro 3) y, auspiciada por Marcel Roche (IVIC), Interciencia en 1976, revista multidisciplinaria que era el medio divulgativo de la federación de organizaciones científicas para el avance de la ciencia en las Américas, la Asociación INTERCIENCIA ${ }^{5}$.

A partir de 1980, comienza a aumentar en forma importante el número de nuevas revistas. Entre 1981 y 1990 se crearon más títulos que en los veinte años precedentes (20), once en la UCV, cinco en la ULA y cuatro en LUZ. Esto debido al importante número de títulos en Ciencias Sociales y humanidades (12), 60\% del total, evidenciando la consolidación de esas disciplinas. Destaca, además, la creación de cuatro títulos en Ciencias naturales y tres en ingeniería y construcción (cuadro 3). Debe señalarse que, hasta esa década, los principales medios divulgativos de las investigaciones sociales y humanísticas eran los libros; la cultura de la publicación de artículos en revistas no estaba muy difundida. En el área de ingeniería, se desarrollaban importantes estudios en organismos técnicos del Estado, pero los resultados eran informes técnicos que, aun constituyendo valiosos aportes de conocimiento, no se divulgaban (literatura gris).

Los Consejos de Desarrollo de las universidades fueron clave en la promoción de las publicaciones en estas décadas. De hecho, al lado de la investigación y los recursos humanos, siempre tuvieron lugar destacado en las estructuras administrativas y programas de estas instancias. Por ejemplo, en 1971, se instituye en LUZ el sistema de publicaciones bajo supervisión del Consejo de Desarrollo (CONDES); entre 1977 y 1980, se aprueba por primera vez financiamiento para revistas, permitiendo la publicación de cinco nuevos títulos (Ferrer de Romero y Rivera, 1998).

\footnotetext{
${ }^{4}$ Estas incluyen botánica, entomología, ciencias de la tierra.

${ }^{5}$ https://www.interciencia.net/acerca-de/asociacion-interciencia/
} 


\section{Cuadro 3}

Creación de revistas académicas

por período (UCV, LUZ, ULA)

\begin{tabular}{|c|c|c|c|c|c|c|c|}
\hline \multirow{2}{*}{ Disciplina } & \multicolumn{6}{|c|}{ Período } & \multirow[b]{2}{*}{ TOTAL } \\
\hline & $1939-1959$ & $1960-1979$ & 1980-1989 & 1990-1999 & 2000-2009 & $2010-2021$ & \\
\hline Agricultura y veterinaria & 2 & 1 & 0 & 2 & 0 & 0 & 5 \\
\hline Ciencias naturales y matemáticas & 3 & 3 & 4 & 4 & 3 & 1 & 18 \\
\hline $\begin{array}{l}\text { Ciencias sociales, educación } \\
\text { comercial y derecho }\end{array}$ & 1 & 3 & 7 & 9 & 6 & 8 & 34 \\
\hline Educación & 0 & 1 & & 4 & 2 & 4 & 11 \\
\hline Humanidades y artes & 1 & 2 & 5 & 8 & 8 & 4 & 28 \\
\hline $\begin{array}{l}\text { Ingeniería, industria y } \\
\text { construcción }\end{array}$ & 0 & 3 & 3 & 0 & 3 & 3 & 12 \\
\hline Multidisciplinaria & 1 & 0 & 0 & 1 & 3 & 7 & 12 \\
\hline Salud y servicios sociales & 3 & 4 & 1 & 4 & 8 & 9 & 29 \\
\hline TICs & 0 & 0 & 0 & 0 & 1 & 2 & 3 \\
\hline TOTAL & 11 & 17 & 20 & 32 & 34 & 38 & 152 \\
\hline
\end{tabular}

Fuente: Elaboración propia a partir de repositorios institucionales

\subsection{Crecimiento y diversificación}

Durante los noventa, en medio de la severa crisis sociopolítica, creció de manera importante el número de nuevos títulos en las tres universidades, catorce en la UCV, ocho en la ULA y, experimentando una gran expansión, diez en LUZ. Prevalecen nuevamente ciencias sociales y humanidades y artes (17), 45\% del total, seguidas por ciencias naturales, salud y servicios sociales, y educación con 12 (4 cada una) (cuadro 3).

En 1990, se crea el Programa de Promoción a la Investigación (PPI), reivindicación que la comunidad académica venezolana exigía desde la década anterior, con el objeto de estimular y reconocer la investigación académica en el país. El programa se centraba en atender los requerimientos de un segmento de la comunidad científica, sin contemplar las necesidades de otros grupos, tales como los tecnólogos de la industria o los docentes de la educación superior (Vessuri, 1996). Se crearon comités de evaluación por áreas de conocimientos, en los que privó, como criterio principal para acreditar a los candidatos a ingresar, la idea de que participaran "todos aquellos que demuestren una producción tangible, verificable y con continuidad en el tiempo" (Vessuri, Martínez Larrechez y Estévez, 2001, p. 101). Se estimulaba la cultura de la publicación en revistas científicas, pero confiriendo la mayor ponderación en la evaluación a las publicaciones en revistas indizadas en el Science Citation Index (SCI).

En consonancia con las políticas y programas de apoyo a las publicaciones científicas que comienzan a desarrollarse en América Latina a principios de esta década, Venezuela da inicio a una serie de iniciativas que contribuyen a fortalecer las revistas académicas nacionales. En 1991, la Fundación para el Desarrollo de la Ciencia y la Tecnología del Estado Mérida (FUNDACITE-Mérida) crea el Índice de Revistas Venezolanas de Ciencia y Tecnología (REVENCYT) con el objetivo de consolidar un registro con la información referencial completa de todos los artículos publicados en las principales revistas venezolanas. Para el año 2000, REVENCYT constituía el mayor registro de revistas científicas del país, para entonces con 140 títulos (SERBIULA, 2020).

Poco después, se crea el Registro de Publicaciones Científicas de Venezuela como parte del programa de apoyo a las publicaciones científicas que inicia, en 1996, el Consejo Nacional de Investigaciones Científicas y Tecnológicas (CONICIT). Tras la creación del Ministerio de Ciencia y Tecnología (1999), este programa pasa al 
FONACIT (Fondo Nacional de Ciencia, Tecnología e Innovación) y se reorienta a fin de darle un carácter más integral, formalizando el proceso de evaluación a objeto de valorizar las revistas nacionales, mejorando su calidad científica y técnica, además de servir como mecanismo para orientar el financiamiento. Así, se crea el sistema de Evaluación Integral de Revistas Científicas y Tecnológicas con el propósito de acreditar "aquellas publicaciones que por su calidad y méritos, contribuyan al incremento de la visibilidad del conocimiento, además de estimular y fomentar la investigación en el país" (APHA, 2008:s.n). De suerte que las revistas que querían obtener la acreditación del FONACIT para optar al cofinanciamiento de sus ediciones impresas e ingresar al Núcleo nacional de calidad, debían someterse al proceso de evaluación cada dos años. El programa de apoyo a las publicaciones de CONICIT/FONACIT en conjunto con el PPI constituyeron un acicate para la creación de nuevas revistas, sobre todo en las áreas de ciencias sociales y humanidades y artes, no tan así en áreas vinculadas a la producción (ingeniería y tecnología y agricultura y veterinaria).

Estas políticas se ven potenciadas con la creación de las plataformas Latindex (1995), SciELO (1998) y REDALYC (2003), proyectos colaborativos de carácter regional dirigidos a conferirle mayor calidad editorial, visibilidad y difusión a las revistas científicas, a través de bases de datos y sistemas de evaluación basados en las particularidades de la región y aplicando sus propios criterios (Alperin y Rozemblum, 2017). Estos repositorios regionales lograron con éxito incrementar la visibilidad de la producción científica publicada en español y portugués, en especial en el campo de las ciencias sociales y humanidades. Esto fue posible, gracias a la gran receptividad e impulso que adquirió el movimiento de Acceso Abierto en nuestros países, región que más extensamente ha impulsado las publicaciones en Acceso Abierto en todo el mundo (Vessuri, Guédon \& Cetto, 2014).

Venezuela no fue ajena a estas iniciativas. A comienzos del siglo XXI buena parte de las revistas académicas existentes se editaban ya en formato electrónico, manteniendo a la par la edición impresa. El acceso abierto fue adoptado por las universidades venezolanas, comenzando por la ULA que fue una de las primeras cuatro universidades latinoamericanas en suscribir la Declaración de Berlín en 2006 y la primera en crear su repositorio institucional (2000), el cual ha servido de modelo para la implantación de los repositorios de otras universidades del país (Contreras, Torrens y Núñez, 2008); todos los cuales pertenecen a la red de repositorios latinoamericanos, lo que les permite la interoperabilidad y el intercambio de información, incrementando aún más la visibilidad de la producción científica que estas instituciones de educación superior generan (Galindo y Ramos de Francisco, 2018).

Como resultado de lo anterior, en la primera década de este siglo se continuó incrementando el número de nuevos títulos, destacando la contribución de LUZ y ULA, 15 y 14 respectivamente, en tanto que en la UCV se reduce a 5 . El impulso en las primeras dos instituciones obedeció a políticas institucionales. Disciplinariamente, destacan salud y servicios sociales, humanidades y artes (16), $55 \%$ del total, seguida de ciencias sociales (3) y Ciencias naturales e ingeniería, industria y construcción con 2 cada una (cuadro 3).

A principios de la década de 2000, el PPI introdujo cambios en los criterios de evaluación permitiendo ampliar las condiciones de ingreso al programa. Uno de los más significativos fue la inclusión de otros índices internacionales distintos al $\mathrm{SCl}$, permitiendo aumentar el número de revistas nacionales consideradas como tipo A, en un momento en el que el Estado asignaba, a través del FONACIT, importantes cantidades de recursos a la promoción de estas publicaciones (Marcano y Phélan, 2009). El impacto de estos cambios fue notable y marcan un punto de inflexión en la evolución del programa. El número de investigadores acreditados aumenta significativamente pasando de 1.687 en 1999, a 5.222 en 2007; siendo el área de ciencias sociales la que experimentó el mayor crecimiento, al pasar de representar el 15\% de los investigadores acreditados en 1990, al 32,78\% en 2007 (Ibídem). 
Por su parte, el Programa Nacional de Evaluación y Cofinanciamiento de las Revistas Científicas Venezolanas del FONACIT, contemplaba para la acreditación de las revistas, su registro en bases de datos nacionales e internacionales (tales como el propio registro de FONACIT, Latindex, REDALYC, DOAJ, CLASE, entre otras) como uno de los indicadores de visibilidad. Por otra parte, las revistas acreditadas que quedaban calificadas en el percentil más alto, eran incluidas en el Núcleo Nacional de Calidad y se les financiaba la publicación de sus ediciones electrónicas en la plataforma SciELO.

Como vimos anteriormente, el número de revistas nacionales experimentó un fuerte crecimiento a partir de la década de 1990, en especial en las área de ciencias sociales y humanas. Del total de 105 revistas en estas áreas identificadas en 2001, 65 títulos (48,6\%) aparecieron en los noventa (Aguilera, 2001, citado por Aguilera, 2012). Crecimiento que vino acompañado de una mejora en la calidad, como puede apreciarse al revisar las cifras en el Registro de publicaciones de FONACIT. Para el año 2000, de las 40 revistas en ciencias sociales registradas (44,4\%), 9 (22,5\%) integraban el Núcleo de calidad. En 2008, los títulos en ciencias sociales representaban el $54,6 \%$ del total de revistas acreditadas (101 de 185), de las cuales, 55 (54,5\%) formaban parte del Núcleo, 13 $(12,9 \%)$ estaban en fase de consolidación y 33 quedaron clasificadas en la lista general (Aguilera, 2012).

\section{3. ¿El fin del boom de las revistas?}

Se había creado una cultura de publicar y una cultura de publicaciones. Esto ayudaría a explicar cómo, a pesar de la suspensión del Programa de Apoyo a las Publicaciones Científicas en Venezuela del FONACIT desde 2009, y de la caída del presupuesto para la investigación en los Consejos de Desarrollo de estas tres instituciones, durante la segunda década del siglo se mantuvo una alta creación de nuevos títulos (33). Pero una revisión más exhaustiva, evidencia una tendencia inercial. Diecinueve de ellas (58\%) se crearon entre 2011 y 2013, once (33\%) entre 2014 y 2017. Desde entonces, evidenciando el agravamiento de la crisis surgen apenas cinco hasta 2021. Institucionalmente, once pertenecen a la UCV, diecinueve a la ULA y cinco a LUZ que, por primera vez, registra una disminución importante en la creación de nuevos títulos (cuadro 3).

Por áreas de conocimiento, destaca el surgimiento de un número importante de revistas multidisciplinarias (7), lo que de alguna manera evidenciaría un sinceramiento de la situación ya que no había suficiente capacidad de producción para las revistas disciplinarias por lo que muchas incluían múltiples temáticas disciplinarias. Se mantiene el crecimiento en salud y servicios sociales (9) y ciencias sociales (8). En ciencias naturales y matemáticas apenas surgió un título nuevo y agricultura y veterinaria, ninguno.

Muchas de estas publicaciones migraron o surgieron bajo formato electrónico, lo cual contribuye a disminuir costos de edición. Esto ayudaría a explicar por qué, aun en situación tan adversa continuaron apareciendo algunas revistas. No obstante, debe mirarse otro aspecto crucial de las publicaciones académicas: su vigencia y continuidad en el tiempo.

\section{Continuidad e impacto de las publicaciones venezolanas}

\subsection{Continuidad}

En el Cuadro 4 se presenta la situación actual de las revistas de las tres universidades analizadas, en términos de su vigencia y continuidad, en donde puede apreciarse que sólo el $44 \%$ de las revistas analizadas están al día., $16 \%$ presentan retraso, mientras que los $40 \%$ restantes están paralizadas.

En una primera mirada al comportamiento de las revistas de las tres universidades, parece que LUZ tiene mejor desempeño al tener casi tres cuartas partes de sus revistas al día y la menor cantidad de revistas retrasadas y paralizadas. Contrariamente al caso de la UCV que tiene el menor porcentaje de revistas al día (29\%) y el mayor de revistas retrasadas (19\%) y paralizadas (52\%). La ULA se encuentra en una situación intermedia con 
aproximadamente el mismo porcentaje de revistas al día y paralizadas ( $42 \%$ cada una). Sin embargo, esa primera apreciación cambia cuando se revisa los años de retraso de las revistas de estas universidades. Así, el promedio de retardo de las revistas de LUZ es de 2,3 años, el de la ULA es de 1,3 años y la UCV que giran alrededor de un año de retardo.

Cuadro 4

Estatus de las revistas por áreas de conocimiento (2010-2020)

\begin{tabular}{|c|c|c|c|c|c|c|c|c|c|}
\hline \multirow[b]{2}{*}{ Área de conocimiento Unesco } & \multicolumn{3}{|c|}{ Al día } & \multicolumn{3}{|c|}{ Retrasadas } & \multicolumn{3}{|c|}{ Paralizadas } \\
\hline & LUZ & UCV & ULA & LUZ & UCV & ULA & LUZ & UCV & ULA \\
\hline Agricultura & 2 & 1 & & & 1 & 1 & & & \\
\hline Ciencias & 3 & 2 & 2 & & 4 & & 1 & 4 & 2 \\
\hline Ciencias sociales, educación comercial y derecho & 9 & 4 & 7 & 1 & & 2 & 1 & 7 & 4 \\
\hline Educación & 1 & 2 & 1 & & & 2 & & 1 & 5 \\
\hline Humanidades y artes & 3 & & 4 & 2 & 2 & 2 & 1 & 8 & 10 \\
\hline Ingeniería, industria y construcción & 2 & & 3 & 1 & & 1 & & 4 & \\
\hline Multidisciplinaria & 4 & 1 & & 1 & 1 & & 2 & 2 & 2 \\
\hline Salud y servicios sociales & 4 & 8 & 7 & & 4 & 1 & & 5 & 1 \\
\hline TICs & & & & & & & 1 & 2 & \\
\hline \multirow{3}{*}{ Total } & 28 & 18 & 24 & 5 & 12 & 9 & 6 & 33 & 24 \\
\hline & \multicolumn{6}{|c|}{26} & \multicolumn{3}{|c|}{63} \\
\hline & \multicolumn{9}{|c|}{159} \\
\hline
\end{tabular}

Fuente: elaboración propia a partir de repositorios institucionales

En cuanto a las áreas temáticas de las revistas que están al día, destacan las áreas de ciencia sociales, educación comercial y derecho y la de salud y servicios sociales que, en conjunto, representan el 56\% (Cuadro 4). De éstas, el mayor aporte de las revistas en ciencias sociales proviene de LUZ y en menor grado de la ULA; mientras que el área de la salud y servicios sociales, destacan las revistas de la UCV y la ULA.

Si bien las décadas de 1980 y particularmente la de 1990 son la época del auge de las revistas académicas, la de 2010 está signada por el declive de las mismas (Gráfico 2), con la paralización de un número importante de ellas. De las 63 revistas que dejaron de circular, 61 lo hicieron durante ese período, muchas de las cuales contaban con una larga trayectoria de entre 40 y 64 años. Todas las áreas de conocimiento sufrieron pérdidas (Cuadro 4), aunque el mayor porcentaje se concentra en humanidades y arte $(30 \%)$ y en ciencias sociales, educación comercial y derecho (19\%).

Como se mencionó, la universidad que más títulos de revistas perdió fue la UCV, y lo hizo en dos de las áreas en las que, comparativamente, cuenta con más publicaciones. De los 18 títulos en el área de ciencias que reúnen estas tres universidades, 10 son de la UCV, de las cuales 4 están paralizados (uno de ellos con 57 años de antigüedad), 4 retrasados y sólo 2 al día. En el área de salud y servicios sociales, 17 de las 30 revistas son de la UCV; de ellas 5 están paralizadas, 4 retrasadas y 8 al día.

La paralización ocurrió mayormente al final de este período. $80 \%$ de los títulos (48) que dejaron de circular durante esta década lo hizo entre 2015 y 2019, de las cuales 26 son de la UCV (54\%), 16 de ULA (33\%) y 6 de LUZ (13\%). En el lapso 2010-2014, si bien la caída fue menos fuerte, no deja de ser significativa con 12 revistas (20\%) repartidas en partes iguales entre la UCV y ULA con 6 cada una. 
Gráfico 2

Paralización de las revistas de

LUZ, UCV y ULA por décadas

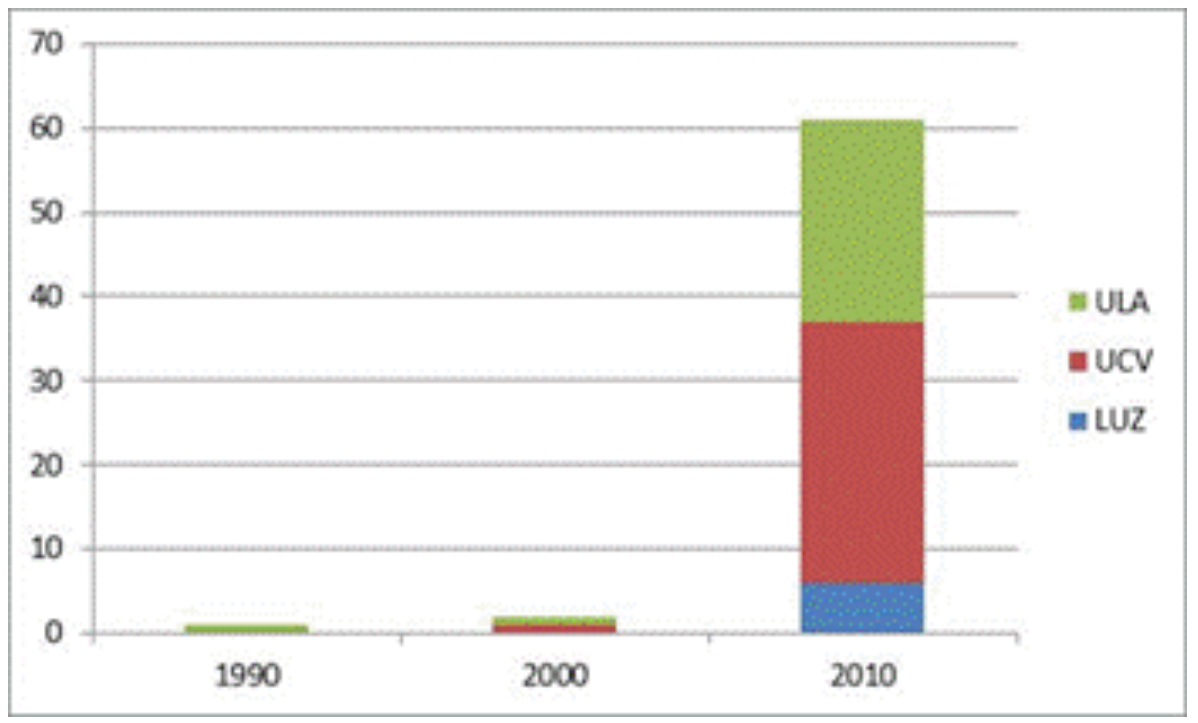

Fuente: elaboración propia a partir de repositorios institucionales

El deterioro de la situación de las revistas académicas de las tres universidades, no solo deriva de la crisis presupuestaria que sufren las universidades autónomas que se viene agudizando desde 2013, sino también y de manera importante, de la política científica desarrollada en el país. En efecto, a finales de la década del 2000 comenzaron a tomarse decisiones de política que trastocaron los avances que se habían logrado hasta entonces en materia de apoyo a la investigación en general, y a las publicaciones científicas en particular.

En 2009, se suspende el Programa Nacional de Evaluación y Cofinanciamiento de las Revistas Científicas Venezolanas que llevaba el FONACIT. Con esta decisión se desmantela toda la estructura construida a lo largo de casi veinte años, restando opciones de financiamiento y mecanismos para el aseguramiento de la calidad. También se cierra el acceso a la biblioteca científica SciELO-Venezuela, que el propio Estado venezolano había estructurado. Al respecto hay que recordar que todos los asuntos relacionados con las actividades de preparación, almacenamiento, diseminación y evaluación de la literatura científica en formato electrónico de SciELO-Venezuela estaban bajo la responsabilidad del Ministerio del poder popular para la Ciencia, Tecnología e Industrias Intermedias, el FONACIT, el Centro Nacional de Tecnología de Información y del Sistema Nacional de Documentación e Información Biomédica, con el apoyo de la Facultad de Medicina de la Universidad Central de Venezuela (APHA, 2008).

Previamente, el FONACIT había comenzado a establecer restricciones que llevaron progresivamente a reducir el número de páginas y el tiraje de los ejemplares. Esto, aunado a la falta de recursos para seguir manteniendo las ediciones impresas, se hizo más acuciante a partir de 2015 (Hernández Fernández, 2016), llevando a las revistas a abandonar la versión impresa para migrar a la digital, y las que no pudieron hacerlo, perecieron.

En 2009 se suspende provisionalmente el PPI que finalmente es sustituido en 2011 por el Programa de Estímulo a la Investigación e Innovación (PEII), el cual marca distancia con respecto al anterior en términos de orientación de política y criterios de evaluación. Entre los criterios para la acreditación de los investigadores, el PEII prioriza las publicaciones en revistas nacionales, lo cual pudiera ser visto como un impulso a las publicaciones venezolanas, aunque resulta paradójico, considerando que el programa de apoyo a las revistas había sido eliminado dos años antes. 
En 2012, el Ministerio de Ciencia, Tecnología e Innovación inicia el proyecto CLaCALIA (Conocimiento latinoamericano y Caribeño de Libre Acceso), plataforma electrónica dirigida a "sistematizar e investigar procesos de comunicación emancipatorios y comunicacionales, (...) el cual se propone sistematizar, visibilizar, validar y legitimar publicaciones periódicas arbitradas y no arbitradas de la producción y la divulgación nacional" (www.clacalia.org6, citado por Ramos de Francisco, 2013:34). La evaluación e indexación para el registro en el Índice Venezolano de Publicaciones Periódicas del FONACIT pasó a estar a cargo de CLaCALIA. Las publicaciones que superasen el $60 \%$ de los ítems del baremo y que, además, cumpliesen con el Código de Ética para la Vida del FONACIT, podían optar a financiamiento (Rivas, 2012). El índice propuesto por esta iniciativa no despertó interés en las revistas académicas locales por no responder a los parámetros y normas establecidas para validar y divulgar la ciencia (Ramos de Francisco, 2013). Hasta dónde se pudo averiguar, el proyecto parece haberse suspendido en 2013.

\subsection{Visibilidad internacional}

El impacto de la pérdida de apoyo a las revistas no sólo se expresa en la dificultad para mantener la periodicidad y permanencia de éstas, sino que también incide en la pérdida de visibilidad de las revistas en el ámbito internacional, afectando con ello también la de la producción científica nacional que circula a través de ellas.

El número de artículos venezolanos en el ranking Scimago de Scopus disminuyó significativamente entre 1994 y 2014 con un claro punto de inflexión en el año 2009 (Aguado-López y Berecelli-García, 2016; Ramírez y Salcedo, 2016). La tendencia a la baja de la producción científica venezolana en los índices internacionales se ha mantenido. Como puede apreciarse en el Cuadro 5, el número de artículos de Venezuela en el Science Citation Index en el año 2017 tuvo una contracción del -31,3\% con respecto a la que tenía en el año 2009.

\section{Cuadro 5}

Relación del número de publicaciones por países de

América Latina y el Caribe registradas en el

Science Citation Index en 2009 y 2017

\begin{tabular}{|c|c|c|c|}
\hline Países & $\mathbf{2 0 0 9}$ & $\mathbf{2 0 1 7}$ & \% 2017 / 2009 \\
\hline Argentina & 8.412 & 11.698 & $39,1 \%$ \\
\hline Brasil & 37.066 & 57.213 & $54,4 \%$ \\
\hline Chile & 5.565 & 10.964 & $97,0 \%$ \\
\hline Colombia & 2.860 & 6.591 & $130,5 \%$ \\
\hline Costa Rica & 479 & 874 & $82,5 \%$ \\
\hline Cuba & 998 & 908 & $-9,0 \%$ \\
\hline Ecuador & 417 & 1.768 & $324,0 \%$ \\
\hline Mexico & 10.916 & 18.623 & $70,6 \%$ \\
\hline Panama & 293 & 580 & $98,0 \%$ \\
\hline Peru & 885 & 2.004 & $126,4 \%$ \\
\hline Uruguay & 727 & 1.399 & $92,4 \%$ \\
\hline Venezuela & 1.548 & 1.063 & $-31,3 \%$ \\
\hline
\end{tabular}

Fuente: Fuente: elaboración propia a partir de: http://www.ricyt.org/2010/07/porpais/

\footnotetext{
${ }^{6}$ ClaCaLIA:http://www.clacalia.org/content/site/module/pages/op/displaypage/page_id/1/format/html
} 
A nivel internacional, Venezuela pasó del puesto 50 que ocupaba en el ranking de Scopus por países en los años 1998-2000, al puesto 93 en el año 2020 (Cuadro 6). Para el año 2015, Venezuela ocupaba la sexta posición de los países de América Latina y el Caribe de este ranking (Ramírez y Salcedo, 2016). Como consecuencia, la contribución de la producción de Venezuela en el contexto regional experimentó una caída del 14,27\%, al pasar de representar el 3,4\% de la producción total de la región en 2005, al 1,44\% en 2014 (Aguado-López y BerecelliGarcía, 2016).

Cuadro 6

Lugar de Venezuela en el Ranking de Scopus por países (1996-2000)

\begin{tabular}{|c|c|}
\hline Año & Posición \\
\hline \hline 1996 & 51 \\
\hline 1998 & 50 \\
\hline 2000 & 50 \\
\hline 2002 & 52 \\
\hline 2004 & 54 \\
\hline 2006 & 56 \\
\hline 2008 & 57 \\
\hline 2010 & 62 \\
\hline 2012 & 66 \\
\hline 2014 & 70 \\
\hline 2016 & 83 \\
\hline 2018 & 90 \\
\hline 2020 & 93 \\
\hline
\end{tabular}

Fuente: Base de datos Scimago varios años

La posición de Venezuela no ha hecho sino descender. De acuerdo al indicador de Scopus que mide la productividad de los países latinoamericanos en el período 2015-2019 (Output 2015-2019), Venezuela ocupa la décima posición y es uno de los países, junto con Argentina, Cuba y Puerto Rico que presentan las menores tasas de crecimiento, produciendo menos artículos científicos que cinco años atrás (Tibaná Herrera, 2021).

El índice regional REDALYC también da cuenta de la caída de la producción venezolana a mediados de la segunda década del 2000. El país, que para el año 2009 acumulaba el mayor número de artículos publicados en esta base de datos, comenzó a descender en 2010 hasta caer en 2014 a niveles, incluso, inferiores a los que tenía en 2005. Su tasa de crecimiento medio acumulado de 2005 a 2014 fue de -2,1\%. En el contexto iberoamericano esto se expresa en una disminución marcada del aporte venezolano a la producción científica de la región, la cual pasó de representar el 5,5\% en 2005, al 3,0\% en 2014 (Aguado-López y Berecelli-García, 2016).

El descenso de la producción venezolana no tuvo el mismo comportamiento en las distintas áreas de conocimiento, siendo las de ciencias sociales y humanidades las que experimentaron la caída más abrupta. En el caso de las ciencias naturales y exactas el declive fue menos drástico, iniciándose en 2012 (Aguado-López y Berecelli-García, 2016). El hecho de que la producción en esta última área se concentra en revistas internacionales, a diferencia de la que se genera en las áreas de ciencias sociales y humanidades cuya producción se concentra en revistas nacionales, puede explicar en parte el retardo en que se visibiliza la caída de la actividad científica en esa área, mas no contrarrestada. 
El declive se aprecia también en la posición de las revistas académicas venezolanas en los distintos sistemas de acreditación internacional. Así, Scopus que tenía registrados 41 revistas venezolanas en 2016, muestra actualmente 31 (Gráfico 3), mientras que Redalyc que contenía 64 revistas, registra sólo 36 en la actualidad (Aguado-López y Berecelli-García, 2016; Scimago Institutions Rankings, 20217; Redalyc.org, 2021 ${ }^{8}$ )

Gráfico 3

Número de revistas venezolanas en Scopus

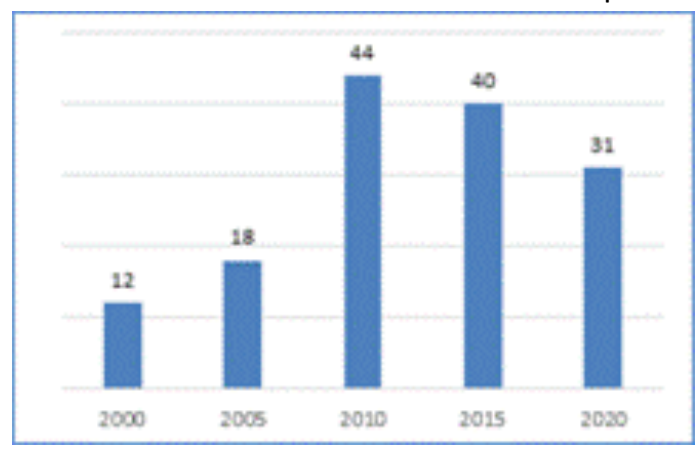

Fuente: Base de datos Scimago varios años

\section{Dinámica actual de las Revistas venezolanas ¿resiliencia o mera sobrevivencia?}

Los resultados, evidencian que, si bien se registra una disminución importante en la actividad de las publicaciones académicas, ésta aparenta ser menos grave que la caída de la investigación. A pesar de las pérdidas sustanciales de financiamiento, un porcentaje importante se encuentran activas e, incluso, un pequeño grupo, en especial en las áreas de ciencias sociales y salud se mantiene en los indizadores internacionales como Scopus, Latindex y REDALYC, sin dejar de reconocer el impactante retroceso que experimentó el país desde 1998. Esto llevó a indagar las razones de este comportamiento.

\subsection{La labor editorial. Navegando con viento en contra}

Este desempeño se sustenta en una labor editorial en condiciones muy adversas que procura mantener las publicaciones, aprovechando, con muchas limitaciones, las oportunidades que ofrece el mundo digital. Se estableció que la mayoría de las revistas se han adecuado al acceso abierto, ampliando el ámbito de las contribuciones de autores. Sin embargo, esto conlleva también riesgos derivados de irregularidades que, globalmente, están afectando a las publicaciones académicas ${ }^{9}$.

Un factor que ha contribuido a la continuidad, y en el caso de muchas publicaciones venezolanas ha sido determinante en su sobrevivencia, es la transición al formato electrónico. Sin embargo, siempre hay costos importantes asociados a la edición (revisión y diagramación) y el montaje en las plataformas. Así, ante la eliminación de las subvenciones por parte del Estado (FONACIT), y la literal desaparición de los presupuestos de

\footnotetext{
${ }^{7}$ https://www.redalyc.org/pais.oa?id=94

8 https://www.scimagojr.com/journalrank.php?country=VE

${ }^{9}$ Nos referimos al fenómeno de las revistas depredadoras y de las revistas secuestradas. Las prácticas predatorias tienen raíces sistémicas. Se ha visto que la comercialización de la investigación académica es un motor principal de las prácticas y comportamientos predatorios. Las prácticas predatorias explotan debilidades en el sistema de evaluación de pares, tales como la falta de transparencia, reconocimiento, calidad y capacidad, y el modelo del "autor paga" ha sido comentado como el principal motor de las prácticas predatorias (IAP, 2021). Nos referimos a las revistas secuestradas, que son parte del proceso general de perversión, más adelante.
} 
los Consejos de Desarrollo u otras instancias de apoyo de las propias universidades a las publicaciones, surgen algunas interrogantes:

¿Cómo están cubriendo las revistas los costos de edición, o cómo logran hacerse de estos servicios? ¿Existirán mecanismos institucionales que les haya permitido afrontar los avatares de la crisis, o serán más bien factores ligados a esfuerzos de carácter individual atribuibles a los editores?

A objeto de conocer la situación, se realizaron entrevistas a editores de seis revistas pertenecientes a la UCV y a la ULA: dos en las áreas de estudios sociales, una en ingeniería y tecnología, una en geografía, una en agricultura y una en ciencias veterinarias. El perfil de los editores evidencia formación de alto nivel, cuatro son PhD y dos aspirantes a doctores, condición fundamental para el desempeño de la función. En la mayoría de los casos, desempeñan otra actividad de importancia (Director de Consejo de Desarrollo, Directora de Instituto, Coordinadoras de Investigaciones de la Facultad, Coordinadora del programa de doctorado) contraviniendo las condiciones para evitar el recargo de responsabilidades que debe tener el editor para llevar adecuadamente su función (García Romero y Martínez-Guerrero, 2018a). Esto revela la precariedad institucional, en la medida que el personal de alto nivel a veces no tiene otra alternativa que asumir diversas funciones para poder garantizar su continuidad.

Con relación a su situación actual, dos de ellas se encuentran al día, dos presentan un retraso de un número, una tiene un retraso de dos números y otra desde finales de 2019. Para 2020, tres se encuentran en el ranking de Scimago de revistas venezolanas (Cuadernos del CENDES, Revista de la Facultad de Ingeniería y Agroalimentaria). En todos los casos, están bajo acceso abierto, y en la actualidad sólo se publican en formato electrónico. Todas migraron desde formato impreso (cuadro 7).

Cuadro 7

Situación de las revistas seleccionadas de la UCV y ULA

\begin{tabular}{|c|c|c|c|c|c|c|}
\hline Revista & $\begin{array}{l}\text { Cuadernos del } \\
\text { CENDES }\end{array}$ & Fermentum & Agroalimentaria & $\begin{array}{l}\text { Revista de la Facultad de } \\
\text { Ingeniería de la Univerisad } \\
\text { Central de Venezuela }\end{array}$ & Terra. Nueva Etapa & $\begin{array}{c}\text { Revista de la Facultad } \\
\text { de Ciencias } \\
\text { Veterinarias, UCV }\end{array}$ \\
\hline Institución & UCV & ULA & ULA & UCV & UCV & UCV \\
\hline Área disciplinaria & $\begin{array}{l}\text { Estudios } \\
\text { Sociales }\end{array}$ & Estudios Sociales & Agricultura & Ingeniería y Tecnología & Geografía & Ciencias veterinarias \\
\hline Formato & Electrónico & Electrónico & Electrónico & Electrónico & Electrónico & Electrónico \\
\hline Acceso abierto & Sí & Sí & Sí & Sí & Sí & Sí \\
\hline Situación actual & Al día & Al día & Retraso 2020 & Retraso 2019 & Retraso 2020 & Retraso 2021 \\
\hline $\begin{array}{l}\text { Recibió apoyo del } \\
\text { CONICIT /FONACIT }\end{array}$ & $\mathrm{Si}$ & Sí & $\mathrm{Si}$ & Sí & SI & SI \\
\hline $\begin{array}{l}\text { Otras fuentes } \\
\text { financimiento }\end{array}$ & $\mathrm{CDCH}$ & $\mathrm{CDCHT}$ & $\mathrm{CDCHT}$ & $\begin{array}{c}\text { CDCH / Fondo Fundación } \\
\text { Andrés Bello }\end{array}$ & $\mathrm{CDCH}$ & $\begin{array}{c}\text { CDCH / Fondo } \\
\text { Fundación Andrés Bello }\end{array}$ \\
\hline $\begin{array}{l}\text { Recibe actualmente } \\
\text { financiamiento }\end{array}$ & No & No & No & No & No & No \\
\hline Cobra a los autores & No & $\begin{array}{c}\text { Solicita } \\
\text { colaboración } \\
\text { voluntaria } \\
\end{array}$ & No & No & No & No \\
\hline
\end{tabular}

Fuente: elaboración propia

Todas recibieron apoyo del programa de apoyo a las Publicaciones Científicas del CONICIT/FONACIT, evidenciando su importancia para consolidar las trayectorias de estas publicaciones. La incorporación en el Registro de Publicaciones Científicas Venezolanas, cumpliendo una serie de requisitos de contenido y edición, les confería mayor visibilidad y les permitía acceder al financiamiento. Esto funcionó hasta la eliminación del 
programa en 2009. Después, continuaron recibiendo financiamiento de los Consejos de Desarrollo de sus instituciones, pudiendo dar continuidad a las revistas, pero teniendo cada vez mayor dificultad para cubrir los costos de edición. Los recursos fueron mermando aceleradamente, y aunque hoy día los programas de financiamiento están vigentes, los montos asignados son tan exiguos que, como indicó uno de los entrevistados, "no alcanza para comprar una resma de papel"10. (Cuadro 7). En la actualidad, ninguna recibe recursos financieros, y no se hacen cobros por publicación ${ }^{11}$ llevando a interrogar ¿cómo logran realizar las labores de edición y diagramación? En el Encuadre 1 se presentan las estrategias implementadas expresadas por los propios editores.

La continuidad de estas publicaciones depende casi exclusivamente del esfuerzo de sus editores y algunos colaboradores. Se observan estrategias resilientes que, si bien no son muy estructuradas, permiten entender cómo han sobrevivido sin respaldo financiero, pero que resultan insostenibles. Esta parece ser la tónica de muchas de las revistas nacionales desde hace ya algún tiempo. Delgado (2011, según Blanco y Grafe, 2019) ya había identificado este comportamiento en un estudio sobre diversas experiencias de publicaciones venezolanas realizado en 2009 donde se exponían apreciaciones de actores directos sobre las condiciones adversas de la actividad editorial:

Hago la revista sin horas asignadas formales. Soy profesor de tiempo completo y dentro de mis tareas tengo dos clases, proyecto de investigación (...), revista, horas de doctorado, comité de tesis y reforma académica (...)

La (universidad) paga el sueldo, (ponen) el nombre, el local, pero no libera carga o paga horas al editor (...)

Los editores son unos campeones, pues hacen todo. Hemos tenido casos en que el editor la suelta y (las revistas) se caen (Delgado, 2011, según Blanco y Grafe (2019), p. 35)

El apoyo institucional es casi inexistente, con la excepción de Cuadernos del CENDES que cuenta con un Departamento de Publicaciones, cuya continuidad, sin embargo, está en entredicho porque su jefa hace ya tiempo está en condición de jubilación. No se valora y se desconoce el valor de este trabajo por parte de las autoridades, como destacó uno de los entrevistados: "la Facultad no ha entendido la importancia que tiene la publicación". Se reclama que, más allá de la existencia de los repositorios institucionales, no haya alguna política institucional que respalde decididamente el esfuerzo editorial.

${ }^{10}$ En el caso de las Revistas de las Facultades de Ingeniería y de Ciencias Veterinarias de la UCV, recibieron financiamiento de la Fundación Fondo Andrés Bello durante los primeros lustros del siglo.

${ }^{11}$ En el caso de la revista Fermentum, se está ensayando con la solicitud de una colaboración no obligatoria a los autores. 


\title{
Encuadre 1
}

Equipo editor de las revistas

\begin{abstract}
El trabajo recae fundamentalmente en el coordinador del Comité editorial y dos miembros (profesores) de la producción editorial. Para diagramación y edición "colaboran con nosotros dos personas del área administrativa. Una de ellas ingresa ahora como investigadora novel. La otra se jubiló, pero entra en el régimen especial de la ULA. Estamos procurando obtener algunos recursos para capacitarla en estas actividades y garantizarle el pago de unos honorarios muy modestos" (A. Gutiérrez, Agroalimentaria, comunicación personal, 6 de diciembre 2021)
\end{abstract}

"La revista tenía dos personas que hacían los trabajos de revisión y edición recibiendo compensaciones económicas muy modestas. Pero llegó un momento en que no se pudo cubrir y dejaron de hacerlo porque tenían que procurar medios para sobrevivir. Nos apoyaba, además, la secretaria de la Coordinación de investigaciones en el seguimiento. Pero ahora está en proceso de jubilación. ¿Qué estamos haciendo? En la plataforma SaberUCV hay un protocolo de publicación. Los borradores de artículos aprobados, se pueden incorporar en el repositorio y pueden ser bajados. Desde el punto de vista técnico están publicados, pero es necesario editarlos para cargarlos. Los artículos de números de 2020 están listos, pero hay que editarlos y subirlos" (R. Sánchez, Revista de la Facultad de Ingeniería de la UCV, comunicación personal, 10 de diciembre de 2021)

"Hasta ahora teníamos dos personas que trabajaban en corrección de estilo y diagramación. Desde noviembre de 2018 cubría sus honorarios, y la actualización del portal Saber UCV, con parte de la prima que cobro como Directora del Instituto. Este año obtuvimos algunos recursos por ingresos propios que permitieron cubrir parte de estas erogaciones. Redalyc, contribuía con nosotros en la edición on-line de los trabajos. Pero ahora exigen que nosotros mismos hagamos la edición bajo el programa Marcalyc. Me dieron una inducción corta, pero es muy trabajoso y no tengo tiempo para eso. En consecuencia, el último número sólo se montó en Saber UCV, gracias a la desinteresada colaboración de la editora de Cuadernos del CENDES" (Karenia Córdova, Terra Nueva Etapa, comunicación personal, 8 de diciembre de 2021)

"Somos cinco personas en el Consejo Editor que junto con el Diagramador y el Corrector nos repartimos las tareas de comunicación, arbitraje, recepción, etc. Me explico: un miembro del CE que es profesor en Diseño Gráfico de la Facultad de Arte, asume la diagramación y usa estudiantes de diseño gráfico a los cuales se les reconoce su trabajo en términos académicos. Yo como Director, todo lo que concierne a recepción y arbitraje. Otro miembro del CE asume corrección y usa estudiantes de letras. Eso es lo esencial, los otros dos nos apoyan con otras cosas. Todo esto ha sido ad honorem hasta ahora, pero hemos decidido darles a todos alguna compensación a partir de 2022". (O. Aguilera, Fermentum, comunicación personal, 9 de diciembre de 2021)

"Yo comencé en el momento en que simplemente desapareció la revista impresa y, entonces o cerrábamos o nos adaptábamos. Se dejó de tener recursos para todo, así que me tocó aprender de la nada. Ahora yo soy la diagramadora y la correctora de estilo y la jefa de publicaciones se ocupa de recibir los artículos, la comunicación con los árbitros y todo lo que tiene que ver con la certificación de las revistas. La indexación es un chip que no me ha logrado entrar. También está el Comité Editor que se ocupa de la revisión de los artículos y la preselección, particularmente una persona, que si se va, me muero porque es de una ayuda inestimable". (C. Iranzo, Cuadernos del CENDES, comunicación personal, 13 de diciembre de 2021)

“El equipo de edición somos dos personas, yo como editora jefe y otra persona que es técnica de diagramación, se ocupa de la diagramación y asume todo el proceso técnico. Ella es personal administrativo de la Facultad asignado a la revista. Tenemos un Comité Editorial pero la mitad o está muerto, o se jubiló o se fue del país." (A.Z. Rivas, Revista de la Facultad de Ciencias Veterinarias-UCV, comunicación personal, 14 de diciembre de 2021)

\subsection{Otros problemas: contribuciones y evaluadores}

En general, como se verá adelante con más detalle, un problema serio de las revistas venezolanas es la disminución de las contribuciones de autores nacionales debido a la caída de la investigación, más notable en las ciencias experimentales o que requieran trabajo de campo. La poca actividad de investigación que se realiza en éstas es mayormente inercial: conclusión de proyectos o aprovechando información generada anteriormente (Mercado, Ávalos, Sánchez-Rose, Cervilla, López \& Vessuri, 2020). Así, un grueso de los artículos en estas áreas se basa en metadatos, lo cual podría estar dando señales erróneas sobre el nivel actual de actividad, si se mide 
por trabajos publicados, colocando más incertidumbre sobre la situación y el devenir de la investigación. En el Encuadre 2 pueden apreciarse los señalamientos de los entrevistados al respecto.

\section{Encuadre 2}

Sobre las contribuciones a las revistas

"El número de artículos nacionales que se recibe ha bajado. Siempre llegan contribuciones, pero en diversos casos no cubren los requisitos. En los últimos tiempos, se ha incrementado la recepción de artículos de autores extranjeros. Es alta de Brasil, Chile y Ecuador" (A. Gutiérrez, Agroalimentaria, comunicación personal, 6 de diciembre de 2021)

"La producción de artículos en la Facultad ha bajado bastante. Por otra parte, el retraso origina que los autores emigren a otras revistas. Haber salido de Scopus, también incide en una disminución del envío de nuevas contribuciones" (R. Sánchez, Revista de la Facultad de Ingeniería de la UCV, comunicación personal, 10 de diciembre de 2021)

"Se reciben pocos artículos. La producción en el área por parte de las universidades nacionales ha bajado muchísimo, y, en algunos casos, no cumplen con los requisitos de la revista. Se están recibiendo algunos trabajos de autores extranjeros" (Karenia Córdova, Terra Nueva Etapa, comunicación personal, 8 de diciembre de 2021)

"Se sigue recibiendo un número de artículos de colaboración de venezolanos que están fuera pero que quieren seguir publicando en Venezuela. Estamos desarrollando una estrategia para que la revista se abra con instituciones de educación superior y postgrado en el extranjero que manden artículos, además de que puedan contribuir económicamente con la publicación. En términos de los autores nacionales, la calidad no ha bajado. La gente que sigue publicando está investigando o están haciendo su postgrado, que los obliga a publicar. El $60 \%-70 \%$ de los autores no tienen problemas en colaborar económicamente con la revista [Se pide un aporte a los autores para la edición de la revista en términos de apoyo voluntaria]." (O. Aguilera, Fermentum, comunicación personal, 9 de diciembre de 2021)

"Está difícil mantenerse al día. Un problema es la falta de financiamiento y otro es la escasez de artículos que se ha venido agravando. Las razones, una es que se le ha dado más valor a las publicaciones en revistas internacionales. Así, los que quieren mayor visibilidad buscan publicar afuera. Otra razón es la alta tasa de rechazo. De cerca de 30 artículos que recibimos, la mitad se descarta, sea porque son de muy baja calidad, sea porque son muy localistas." (C. Iranzo, Cuadernos del Cendes, comunicación personal, 13 de diciembre de 2021)

“En año y medio recibimos un solo artículo científico. Como resultado de un curso de ampliación que se hizo en noviembre pasado, resultaron revisiones, todas de excelente calidad que estamos repartiendo en diferentes números. Otra cosa que activó la Facultad son las pasantías de grado, en la que los estudiantes deben elaborar casos clínicos, lo que ha permitido cubrir esa parte. Podría hacerse metadata pero no hay cultura de publicación en la parte clínica." (M.Z. Rivas, Revista de la Facultad de Ciencias Veterinarias-UCV, comunicación personal, 14 de diciembre de 2021)

Se evidencian causas que se retroalimentan, que permiten explicar la pérdida de impacto de las publicaciones nacionales en los indizadores internacionales. La disminución del número de contribuciones por parte de autores nacionales, por la caída de la actividad de investigación y, en algunos casos, derivado de las contribuciones que se rechazan por calidad, contribuye al retraso en la edición, afectando la permanencia de las revistas en los 
repositorios. A su vez, el retraso y la salida de los repositorios, desestimula el sometimiento de artículos por potenciales autores.

La evaluación de artículos por parte de los árbitros es otro problema serio. La pérdida de profesoresinvestigadores en las universidades, gran parte de los cuales se encontraba en niveles intermedios y altos de la carrera académica y poseían experiencia en investigación, dificulta realizar la actividad. Además, los editores se ven bastantes limitados en exigirles a los árbitros el cumplimiento de los plazos, porque los arbitrajes se hacen como colaboración a la revista, sin remuneración (Encuadre 3).

\title{
Encuadre 3
}

Sobre el arbitraje

\begin{abstract}
"El sistema de evaluación doble ciego se dificulta muchísimo. Hay que considerar que son voluntarias, no se hace remuneración alguna, por lo que suelen presentarse muchos retrasos. Se elaboró una base de datos de los recursos existentes, y se incluyen autores cuyas publicaciones hayan sido aceptadas en la Revista. Los brasileños han resultado buenos colaboradores". (A. Gutiérrez, Agroalimentaria, comunicación personal, 6 de diciembre de 2021)
\end{abstract}

"Es difícil conseguir árbitros. Se les reconoce y se les estimula otorgándoles constancias de arbitraje. Procuramos profesionales que trabajen el tema relacionado con el área en otras universidades y centros de investigación. Antes lo hacíamos también con técnicos de organismos públicos. En estos momentos nos apoyamos, en gran medida, en profesores jubilados" (K. Córdova, Terra Nueva Etapa, comunicación personal, 8 de diciembre de 2021)

"Lo abordamos a través del Comité Editorial, bajo la figura de editores invitados que es un grupo decisor que colabora con la Revista" (R. Sánchez, Revista de la Facultad de Ingeniería de la UCV, comunicación personal, 10 de diciembre de 2021).

"Cada vez es más difícil conseguir árbitros que participen gratis. Comienzan a exigir cobro" (P. Aguilera, Fermentum, comunicación personal, 9 de diciembre de 2021)

"Tenemos problemas serios para conseguir árbitros. Un problema es que los árbitros acepten artículos sin cobrar, otro problema es que cumplan con los tiempos" (C. Iranzo, Cuadernos del Cendes, comunicación personal, 13 de diciembre de 2021)

"Los árbitros nos han respondido muy bien. Pedimos un internacional y dos nacionales y hasta ahora han colaborado de forma gratuita desde que FONACIT eliminó el financiamiento para arbitraje. Quieren ayudar para que la revista siga activa" (A.Z. Rivas, Revista de la Facultad de Ciencias Veterinarias-UCV, comunicación personal, 14 de diciembre de 2021)

Un tema relevante es mantener la calidad de la evaluación, que demanda altos niveles de formación. Pero en cuanto a condiciones, no hay otra forma de hacerlo sino como colaboración. Informalmente, consiguen crear redes con personas dispuestas a contribuir desinteresadamente, que permiten realizar la actividad, con las limitaciones que esto conlleva.

Este sería el segundo factor que ayudaría a explicar la sobrevivencia y continuidad de las revistas, a pesar de no contar desde hace bastante tiempo con algún financiamiento y la carencia de políticas institucionales que regule la actividad. Ello demuestra que existe una capacidad de resiliencia no desestimable que, como se señaló, deriva de la conformación de una cultura de publicaciones. 


\section{4. ¿Quiénes están publicando en las revistas venezolanas?}

Otra arista importante para comprender la sobrevivencia de las revistas es conocer qué están divulgando, llevando a examinar el origen de los artículos ¿muestran el nivel de la actividad de investigación nacional? ¿Se está ampliando el espectro con contribuciones de autores de otros países? Uno de los señalamientos que se han realizado en el pasado a las publicaciones nacionales, ha sido su tendencia a ser endogámicas, no sólo en cuanto al país, sino de las propias instituciones a las que pertenecen, cuestión que se traducía en un predominio de autores locales, factor que contribuía a limitar su proyección (García Romero y Martínez-Guerrero, 2018b).

Se tomó como muestra las seis revistas cuyos editores fueron consultados, considerando el período 2005-2020, presentando datos cada cinco años ${ }^{12}$. En concordancia con la tendencia observada en la evolución del número de revistas, se observa un incremento del número de artículos hasta 2015, registrándose una fuerte disminución en 2020 (cuadro 8).

Para 2005, la contribución de autores extranjeros era baja (10\%), observándose que, de manera general, ha crecido sostenidamente constituyendo el $36 \%$ en 2020. Dos de las tres revistas que aparecen en el ranking Scimago 2020 (Cuadernos del Cendes y Agroalimentaria), han contado, al menos desde 2005, con importante porcentaje de publicaciones de autores extranjeros. No obstante, este valor se incrementó notablemente desde 2015, alcanzando, en el caso de Agroalimentaria, 85\% en 2020.

La Revista de la Facultad de Ingeniería, ha constituido un medio de divulgación importante de la producción nacional en las áreas tecnológicas, observándose en estos años participación de diversas universidades y centros de investigación como el IVIC y de I+D como INTEVEP. Presenta notable ritmo de publicación de artículos, superior a 40 anuales hasta 2015, año en que se observa el mayor número de contribuciones de autores extranjeros sin llegar a ser significativos (15\%). Sin embargo, el número de artículos cae alrededor de la mitad en 2020, con apenas un artículo de autor extranjero (cuadro 8).

\section{Cuadro 8}

Evolución de las publicaciones por origen

(nacional-extranjero) en cinco revistas nacionales

\begin{tabular}{|c|c|c|c|c|c|c|c|c|c|c|c|c|c|c|c|c|}
\hline \multirow[b]{2}{*}{ Revista } & \multicolumn{4}{|c|}{2005} & \multicolumn{4}{|c|}{2010} & \multicolumn{4}{|c|}{2015} & \multicolumn{4}{|c|}{2020} \\
\hline & $\begin{array}{c}\text { Artículos } \\
\text { nacionales }\end{array}$ & $\begin{array}{c}\text { Artículos } \\
\text { extranjeros }\end{array}$ & Total & $\begin{array}{c}\% \\
\text { Ext/total }\end{array}$ & $\begin{array}{c}\text { Artículos } \\
\text { nacionales }\end{array}$ & $\begin{array}{c}\text { Artículos } \\
\text { extranjeros }\end{array}$ & Total & $\begin{array}{c}\% \\
\text { Ext/total }\end{array}$ & $\begin{array}{c}\text { Artículos } \\
\text { nacionales }\end{array}$ & $\begin{array}{c}\text { Artículos } \\
\text { extranjeros }\end{array}$ & Total & $\begin{array}{c}\% \\
\text { Ext/total }\end{array}$ & $\begin{array}{c}\text { Artículos } \\
\text { nacionales }\end{array}$ & $\begin{array}{c}\text { Artículos } \\
\text { extranjeros }\end{array}$ & Total & $\begin{array}{c}\% \\
\text { Ext/total }\end{array}$ \\
\hline Cuadernos del CENDES & 8 & 7 & 15 & $46,7 \%$ & 10 & 5 & 15 & $33,3 \%$ & 4 & 13 & 17 & $76,5 \%$ & 6 & 6 & 12 & $50,0 \%$ \\
\hline Fermentum & 23 & 0 & 23 & $0,0 \%$ & 15 & 1 & 16 & $6,3 \%$ & 17 & 3 & 20 & $15,0 \%$ & 22 & 6 & 28 & $21,4 \%$ \\
\hline Agroalimentaria & 10 & 3 & 13 & $23,1 \%$ & 9 & 10 & 19 & $52,6 \%$ & 6 & 12 & 18 & $66,7 \%$ & 3 & 17 & 20 & $85,0 \%$ \\
\hline \begin{tabular}{|l|} 
Revista de Ciencias \\
Veterinarias. Universidad \\
Central de Venezuela \\
\end{tabular} & 10 & 0 & 10 & $0,0 \%$ & 12 & 0 & 12 & $0,0 \%$ & 9 & 3 & 12 & $25,0 \%$ & 4 & 0 & 4 & $0,0 \%$ \\
\hline \begin{tabular}{|l|} 
Revista de la Facultad de \\
Ingeniería de la Univerisad \\
Central de Venezuela*
\end{tabular} & 39 & 1 & 40 & $2,5 \%$ & 43 & 2 & 45 & $4,4 \%$ & 41 & 7 & 48 & $14,6 \%$ & 20 & 1 & 21 & $4,8 \%$ \\
\hline Terra. Nueva Etapa & 6 & 0 & 6 & $0,0 \%$ & 10 & 1 & 11 & $9,1 \%$ & 9 & 1 & 10 & $10,0 \%$ & 6 & 4 & 10 & $40,0 \%$ \\
\hline Total & 96 & 11 & 107 & $10,3 \%$ & 99 & 19 & 118 & $16,1 \%$ & 86 & 39 & 125 & $31,2 \%$ & 61 & 34 & 95 & $35,8 \%$ \\
\hline
\end{tabular}

Fuente: Elaboración propia

${ }^{12}$ En el caso de la Facultad de Ingeniería, estaban disponibles los datos de 2006. 
La Revista de Ciencias Veterinarias recibía, hasta 2010, contribuciones fundamentalmente de las Facultades de Agronomía y Veterinaria de la UCV. Para 2015 se observa alguna diversificación con publicaciones de otras universidades nacionales y tres artículos del exterior. Para 2020, registra una abrupta caída, publicándose apenas un tercio de lo que se publicaba en los años precedentes analizados, sin ninguna contribución del exterior.

Los datos de estas dos revistas evidenciarían cómo las áreas tecnológicas, conjuntamente con las de ciencias naturales y matemáticas, han sufrido el impacto de la crisis en el país. La paralización de Acta Científica Venezolana desde 2018, revista icónica de las ciencias naturales y matemáticas del país es la constatación más evidente de esta situación. Por su parte, la retracción de las contribuciones de autores no nacionales en el caso de la Revista de la Facultad de Ingeniería se debe, en parte, a que la Revista fue secuestrada; la sustracción de identidad ha originado problemas, entre ellos, reclamos de parte de autores timados, que se enteran a través del Consejo Editorial, que el sitio web donde enviaron su artículo no tiene relación con la Revista ${ }^{13}$.

Las otras dos revistas de ciencias sociales, han mantenido una importante difusión de publicaciones de diversas universidades nacionales, manteniendo un número de publicaciones más o menos continuo en el período considerado, observándose, sí, un progresivo aumento de las contribuciones de autores extranjeros, sobre todo en 2020 (cuadro 8).

El aumento de las contribuciones de autores no nacionales, en medio de la pérdida de impacto de las publicaciones nacionales en las bases de datos internacionales, resultaría un contrasentido. Consultados los editores, explicaron que esto obedece a varios factores entre los que destacan al surgimiento de capacidades de investigación en algunos países de la región, acompañados de la exigencia de publicar en revistas de trayectoria e indizadas. Se observa que buen número artículos proviene de Ecuador, aunque son también importantes las contribuciones de Brasil y Argentina. Ampliando un poco más el análisis, en el caso de algunas revistas de la Universidad del Zulia, se observa, en general, un incremento muy importante de contribuciones de universidades de la región nororiental colombiana, de Centroamérica y Suramérica. Así, las revistas que aún se mantienen en los índices, resultan de interés para publicar ¿constituye esto una bomba de oxigeno que está prolongando la vida de las revistas? Y, ante la pérdida progresiva de posiciones de éstas en los repositorios internacionales ¿puede mantenerse esta tendencia?

En otros casos, se ha observado también interés de países de otras regiones por publicar en las revistas de áreas tecnológicas, en especial de China y Medio Oriente. Pero, según algunos de los editores, presentan propuestas poco transparentes que llegan a considerar pagos por la publicación en desmedro de la evaluación, cuestión que, en el caso de las revistas analizadas, ha sido rechazado de plano.

Sin duda, el acceso abierto, con las amplias posibilidades que proporciona el mundo virtual, abre ventanas de oportunidad a la producción y difusión del conocimiento en condiciones adversas, pero también amenazas ante las cuáles no parecen existir capacidades institucionales para afrontarlas.

Los resultados plantean efectivamente una disyuntiva. No existen dudas con relación a que la sobrevivencia de las revistas en gran medida se debe a los encomiables esfuerzos de los editores que, en medio de la debacle de la investigación en el país, procuran contribuciones, asumen labores editoriales y administrativas, y conforman redes colaborativas informales. Tampoco hay dudas de que se han beneficiado de la coyuntura del avance de la

${ }^{13}$ La rápida evolución de los modelos de publicación ha creado un terreno fértil para prácticas crecientemente no éticas de explotación de los académicos. Dichas prácticas se ciernen sobre sistemas que se han vuelto muy vulnerables, como el venezolano. 
investigación en países de la región que procuran medios para divulgar su trabajo. En ese sentido, el impulso dado a las publicaciones nacionales durante los noventa y la primera década del 2000 puede haber creado un acervo que en la actualidad puede dar cabida a estas demandas. Por otra parte, algunos programas e iniciativas tales como los programas de apoyo a las revistas desarrollados de los $\mathrm{CDCH}$, así como el desarrollo de talleres a los editores que éstos han dictado, ayudan a adecuarse a las nuevas demandas y dar continuidad a los esfuerzos, pero la asfixia presupuestaria impuesta a las universidades amenaza la viabilidad continuada de esos esfuerzos. Si bien los repositorios de las universidades han permitido aumentar la visibilidad de la producción científica y de las revistas nacionales, evidenciando importantes niveles de resiliencia, en la actualidad se discute mucho acerca de cuáles serían las estrategias de sobrevivencia de las publicaciones científicas.

La combinación de la caída de la investigación, la precariedad financiera, y la falta de una clara política institucional, atentan contra la calidad y la continuidad de las revistas. De allí la perdida de visibilidad e impacto en el ámbito internacional. Así, es plausible inferir que estos esfuerzos, y la cada vez más complicada continuidad de las publicaciones académicas, son simplemente los estertores de la investigación en Venezuela.

\section{Referencias bibliográficas}

Aguado-López, E., y Becerril-García, A. (2016). Producción científica venezolana: apuntes sobre su pérdida de liderazgo en la región latinoamericana. Revista Venezolana de Gerencia, 21(73), 11-29

Aguilera, O. (2001). Las revistas en ciencias sociales a finales del siglo XX. Acta Científica Venezolana, 52(2).

Aguilera, O. (2012). Integración en América Latina en ciencias sociales. El caso de sus revistas científicas. Nuevo Mundo, IV(8), 19-42

Alperin, J., Rozemblum, C. (2017). La reinterpretación de visibilidad y calidad en las nuevas políticas de evaluación de revistas científicas. Revista Interamericana de Bibliotecología, 40 (3), 231-241. DOI: 10.17533/udea.rib.v40n3a04

APHA (2008). Compendium y la evaluación de mérito de las publicaciones científicas y tecnológicas venezolanas. Compendium, 11(21), Editorial. Recuperado de: http://www.redalyc.org/articulo.oa?id=88011723001

Aula Abierta (2020). Informe preliminar: afectaciones a la educación de calidad en las universidades públicas venezolanas en el marco del COVID-19. Recuperado de: http://aulaabiertavenezuela.org/wpcontent/uploads/2020/04/afectaciones-a-la-educaci\%c3\%93n-de-calidad-en-las-universidadesp\%c3\%9ablicas-venezolanas-en-el-marco-del-covid-19-1.pdf

Contreras, H.Y,. Torrens, R. y Núñez, L.A. (2008). Repositorio institucional www.saber.ula.ve: Una aproximación testimonial. Conferencia Interna IADIS - International Association for Development of the Information Socity. Recuperado de: http://www.saber.ula.ve/handle/123456789/26128

Delgado, J. (2011). Journal publication in Chile, Colombia and Venezuela: University responses to global, regional, and national pressures and trends. (Unpublished doctoral dissertation). University of Pittsburgh. School of Education. Pittsburgh, PA, USA. http://revistacts.net/files/Jorge_Delgado_Dissertation_ETD_08192011.pdf

Blanco, C.E. y Graffe, G. (2020). Gestión de la divulgación de conocimientos: universidad y revistas especializadas en Venezuela. Mikarimin. Revista Científica Multidisciplinaria. 6(2000). Edición Especial, 2942. 
Diaz, E., Texera, Y. y Vessuri, H. (Edits). La Ciencia Periférica. Caracas: Monte Ávila Editores

Diez, E., Freites, Y., García-Pérez, M., Ordóñez, L., Pineda, J., Requena, J. \& Romero, S. (2020). Venezuelan research community migration: impacts and public policy. Discussion Paper №IDB-DP-814. Inter-American Development Bank. DOI: http://dx.doi.org/10.18235/0002776

Ferrer de Romero, J. y Rivera. A (1998). Investigación y universidad contemporánea. Caso Universidad del Zulia. Revista de Ciencias Sociales, IV(2). https://doi.org/10.31876/rcs.v412.25032

Galindo, L. y Ramos de Francisco, C. (2018). Repositorios académicos de acceso abierto en Venezuela. Tribuna del Investigador, 19(2), 96-103.

García Romero, M. y Martínez-Guerrero, C. (2018b). 20 Años de Aldea Mundo: Aportes y Desafíos de una Revista Científica Venezolana Sobre Fronteras e Integración. Aldea Mundo, 23(45), 69-81.

García Romero, M. y Martínez-Guerrero, C. (2018a). El perfil del editor en la gestión de las revistas científicas venezolanas. Revista Venezolana de Gerencia, 23(1), 311-327.

https://doi.org/10.37960/revista.v23i1.24470

Hernández Fernández, Lissette (2016). Presupuesto universitario deficitario y la vigencia de la revistas científicas... Revista de Ciencias Sociales (Ve), XXII(1), 7-8.

IAP (2021). Combatting Predatory Academic Journals and Conferences. Inter Academy Partnership, 24 September. Final Draft.

Knöchelmann, M. (2020). The Democratization Myth: Open Access and the Solidification of Epistemic Injustices (PreprintMai 2020). Recuperado de: https://osf.io/preprints/socarxiv/hw7at/

Marcano, D. y Phélan, M. (2009). Evolución y desarrollo del Programa de Promoción del Investigador en Venezuela. Interciencia, 34(1), 17-24.

Mercado, A., Ávalos, I., Sánchez-Rose, I., Cervilla, M., López, S. \& Vessuri, H. (2020). Capacidades de ciencia, tecnología e innovación para superar la crisis en Venezuela. Technical Report Prepared for the International Development Research Center (IDRC) and the Global Development Network (GDN). October 2020.

Mercado, A., Testa, P., Rengifo, R., Goméz, N. y Patruyo, T. (1999). El ofertismo limitado: una aproximación al sistema nacional de innovación venezolano. Espacios. 20 (2), s.p. Disponible en: https://www.revistaespacios.com/499v20n02/10992002.html

Mirowski, Ph. (2018). The future(s) of open science. Social Studies of Science, 48(2), 171-203.

Observatorio Nacional de Ciencia, Tecnología e Innovación (2017). Indicadores Venezolanos de Ciencia, Tecnología e Innovación. Boletín año 2017. Ediciones ONCTI

Packer, A. (18 de diciembre de 2019). EL modelo SciELO de publicación como política pública de acceso abierto [Blog SciELO en Perspectiva]. Recuperado en: https://blog.scielo.org/es/2019/12/18/el-modelo-scielo-depublicacion-como-politica-publica-de-acceso-abierto/\#.Xf5800dKiUk

Polanyi, M. (2014). La República de la Ciencia: su teoría política y económica. Revista CTS, 27(9). 185-203.

Ramírez, T. y Salcedo, A. (2016). Inversión y producción científica en Venezuela ¿una relación Inversamente proporcional? Revista de pedagogía, 37(101), 147-174. 
Ramos de Francisco, C. (2013). Situación de la investigación de las publicaciones científicas en las universidades autónomas del país. Derecho de palabra de la Vicepresidente de la APIU/UCV, ante el Núcleo de los CDCH de las Universidades Autónomas, LXIII Convención Anuale de AsoVAC, Valencia 28/11/2013. Tribuna del Investigador, 14(1-2),32-36.

Rivas, P. (2012). FONACYT-CLACALIA evalúa favorablemente a Educere y ULA la galardona otra vez (Editorial). Educere, 16(55), 245-248.

SERBIULA (2020). Reseña Histórica REVENCYT. Recuperado de: http://bdigital2.ula.ve/bdigital/index.php/quienes-somos/resena-historica

Testa, P. (2002). Indicadores Científicos y Tecnológicos en Venezuela: de las Encuestas de Potencial al Observatorio de Ciencia, Tecnología e Innovación. Cuadernos del CENDES, 52(51), 43-64.

Tibaná Herrera, G. (30 de abril de 2021). Latinoamérica: producción científica y tendencias de crecimiento [Blog SCImago Lab]. Recuperado de: https://www.scimagolab.com/tag/venezuela/

Vessuri, H. (2005). Ciencia, política e historia de la Ciencia Contemporánea en Venezuela. Revista Venezolana de Economía y Ciencias Sociales, 11(1), 65-87.

Vessuri, H. (1996). La calidad de la investigación en Venezuela: elementos para el debate en torno al Programa de Promoción del Investigador. Interciencia, 21(2), 98-102.

Vessuri H., Guédon, J.C., \& Cetto, A.M. (2014). Excellence or quality? Impact of the current competition regime on science and scientific publishing in Latin America and its implications for development. Current Sociology, 2014(62), 647-665. DOI: 10.1177/0011392113512839

Vessuri, H.; Martínez Larrechez. E. y Estévez, B. (2001). Los científicos sociales en Venezuela. Perfil bibliográfico e implicaciones de política. Cuadernos del Cendes, 18(48), 89-121.

Yokoi, K. (2013). The Growth of Open Access Journals in Relation to the Publication of Scholarly Journals. Library and Information Science, 2013(70), 143-175.

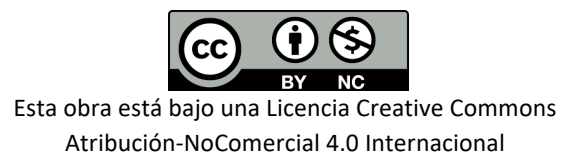

